\title{
SISTEMA DE MONITORAMENTO AUTOMATIZADO
}

\section{Aline Goulart ${ }^{1}$ \\ Raiane Viana ${ }^{2}$ \\ Valdir Gil Pillat ${ }^{3}$}

Resumo: Atualmente existe uma grande necessidade de ter sistemas que auxiliem no monitoramento de ambientes, por exemplo: uma residência; permitindo assim que o usuário possa controlar e ter acesso a tudo que acontece quando o mesmo estiver ausente. Este projeto propõe realizar o desenvolvimento de um sistema de monitoramento automatizado, cujo objetivo é identificar a presença de pessoas e capturar temperaturas de um ambiente. O sistema é composto por um microcontrolador Arduíno, no qual estará acoplado: uma Webcam, sensores de presença e temperatura e um módulo wifi, que possibilitará o envio dos dados capturados ao servidor web. No protótipo desenvolvido foram implantados todos os recursos definidos com base nos requisitos do usuário, dentre os quais podem-se destacar: permitir detectar a presença de pessoas em ambiente, capturar imagens, capturar temperatura em um intervalo de tempo específico e enviar todos os dados para o servidor; permitir que o usuário visualize as informações capturadas através de um site; gerar relatórios e gráficos com as informações capturadas e permitir que o usuário exporte as informações em formato de arquivo.

Palavras-chave: Automação Residencial; Microcontrolador Arduino; Linguagem C; Sensores.

\footnotetext{
1 Engenharia da Computação/Univap, Brasil. E-mail: aline.mgoulart@gmail.com.

2 Engenharia da Computação/Univap, Brasil. E-mail: raianevianas@gmail.com.

${ }^{3}$ Ciências da Computação/Univap, Brasil. E-mail: valdirgp@univap.br.
} 